Magda Duarte dos Anjos Scherer ${ }^{1}$

Denise Elvira Pires de Pires ${ }^{2}$

Rémy Jean ${ }^{2}$

${ }^{1}$ Departamento de Saúde Coletiva, Faculdade de Ciências da Saúde,

Universidade de Brasília. Campus Universitário

Darci Ribeiro. 70910-900

Brasília DF Brasil.

magscherer@hotmail.com

${ }^{2}$ Departamento de

Enfermagem, Centro de

Ciências da Saúde,

Universidade Federal de

Santa Catarina.

${ }^{3}$ Institut d'Ergologie,

Aix-Marseille Université.

\section{A construção da interdisciplinaridade no trabalho da Equipe de Saúde da Família}

\author{
The implementation of interdisciplinarity \\ in the work routine of the family health care team
}

Abstract Interdisciplinarity in the work routine of professionals of a Residency Course on Family Health in Southern Brazil was investigated in a qualitative study involving 11 residents and $5 \mathrm{su}$ pervisors of seven professions. Through interviews, observations and focal groups the existence of interdisciplinarity in practice was analyzed, duly identifying favorable and unfavorable aspects for its implementation. Interdisciplinarity was expressed as a complex process and concrete action, which occurs in the dramatic implications of its usage, in a dialectical relationship with the political and institutional context. The study revealed that working in family health care renders the work more complex and that the professionals experience difficulties in sharing knowledge and making the transition between multidisciplinarity and interdisciplinarity. The study concludes that interdisciplinarity requires the integrated use of knowledge in the multi-professional practice, the crossing of disciplinary boundaries, the development of competencies to address the challenges of the work environment and personal attitude as a basic component for professional action.

Key words Work, Oganization and administration, Patient care team, Health Services, Human resources, Family health care, Ergology
Resumo Investigou-se a interdisciplinaridade no trabalho de profissionais de um Curso de Residência em Saúde da Família na Região Sul do Brasil em um estudo qualitativo com 11 residentes e 5 supervisores de sete profissões. Através de entrevistas, observação e grupo focal analisou-se a vivência da interdisciplinaridade, identificando elementos facilitadores e dificultadores. A interdisciplinaridade foi expressa como um processo complexo e de ação concreta, que ocorre nas dramáticas do uso de si, numa relação dialética com o contexto político institucional. O estudo evidenciou que trabalhar na saúde da família complexifica o trabalho e que os profissionais vivenciam a dificuldade de compartilhar saberes e de transitar entre o multi e o inter. Conclui-se que a interdisciplinaridade requer uso integrado de conhecimentos na prática multiprofissional, invasão das fronteiras disciplinares, desenvolvimento de competências para lidar com os desafios do meio e atitude individual como componente fundamental para o agir profissional.

Palavras-chave Trabalho, organização e administração, Equipe de assistência ao paciente, Serviços de Saúde, Recursos humanos, Saúde da família, Ergologia 


\section{Introdução}

O movimento histórico de produção do conhecimento que formou diversas disciplinas se refletiu no campo da saúde e influenciou a conformação de diversos núcleos profissionais. As diversas profissões de saúde têm um objeto de trabalho comum que é o ser humano com carências de cuidado em saúde ${ }^{1}$. Este objeto complexo e multidimensional demanda uma abordagem multiprofissional e interdisciplinar, no entanto, contraditoriamente, cada profissão se estrutura com paradigmas e experiências específicas que vão compor modos distintos e fragmentares de atuar ${ }^{1,2}$.

A complexidade do processo saúde doença e a necessidade de uma abordagem interdisciplinar têm sido debatidas por diversos autores ${ }^{3-12}$. A natureza multidimensional do ser humano requer práticas profissionais interdisciplinares que possam engendrar "formas mais abrangentes e totalizadoras de aproximar-se da realidade" ${ }^{13}$, coerentes com os princípios da universalidade, equidade e integralidade da atenção que norteiam o Sistema Único de Saúde (SUS) brasileiro.

O contexto brasileiro pós-Constituição de 1988 tem sido favorável ao desenvolvimento de propostas inovadoras no sentido de provocar mudanças no processo de trabalho em saúde orientadas pelos princípios do SUS. A Estratégia de Saúde da Família (ESF), incorporada à Política Nacional de Atenção Básica (PNAB) ${ }^{14}$, como é chamada a política brasileira de atenção primária, inclui aspectos inovadores para o trabalho em saúde em relação ao modelo biomédico vigente. Para substituir o modelo biomédico hegemônico ${ }^{15}$ - centrado no indivíduo, no diagnóstico e tratamento das doenças, na fragmentação do ser humano e do trabalho e na assistência médica curativa e hospitalar - a ESF propõe o foco na família e comunidade, adscrição de clientela, valorização dos diversos saberes e práticas, integralidade e intersetorialidade das ações e estabelece que o trabalho multiprofissional deva ser interdisciplinar e em equipe ${ }^{14}$.

Nesse cenário, entendendo que a educação dos profissionais para serem protagonistas de novas práticas é estratégica, o Ministério da Saúde passou a investir em residências multiprofissionais em todo o país. Partindo do pressuposto de que esse contexto de formação é propício para que a interdisciplinaridade aconteça, o presente estudo teve por objetivo analisar a vivência da interdisciplinaridade nas práticas de profissionais que participaram de um Curso de Residência Multiprofissional em Saúde da Família em um município da Região Sul do Brasil, a partir das percepções e expressões dos residentes e supervisores. Buscou-se identificar elementos facilitadores e dificultadores da prática interdisciplinar. Apesar de se tratar de um contexto de formação, a pesquisa concentrou-se na análise das práticas profissionais, não tendo a pretensão de analisar a política de educação em saúde ou o Curso de Residência.

A interdisciplinaridade, neste estudo, é entendida como instrumento e expressão de uma crítica do saber disciplinar e como uma maneira complexa de entendimento e enfrentamento de problemas do cotidiano. Exige a integração não somente de saberes, mas também de práticas, e integra e renormaliza as disciplinas e as profissões delas decorrentes, concretizando, ao final, a íntima relação entre conhecimento e ação. $\mathrm{Ou}$ seja, falamos aqui de uma interdisciplinaridade como processo de construção de conhecimento e ação, a partir de finalidades compartilhadas por coletivos de trabalho. Implica em um posicionamento ético e político que exige diálogo e negociação para definição das competências necessárias para a resolução dos problemas enfrentados ${ }^{16}$.

Os conceitos de Campo e Núcleo ${ }^{17}$ contribuem para tratar da necessidade de articular diferentes competências e responsabilidades de maneira a combinar a necessidade de polivalência e, ao mesmo tempo, de especialização, assim como de lidar com a autonomia e a definição de responsabilidades no trabalho em saúde. Estes conceitos guardam estreita relação com o de interdisciplinaridade que adotamos e ajudam a analisar a sua expressão nas práticas profissionais. $\mathrm{O}$ núcleo seria "o conjunto de saberes e de responsabilidades específicos de cada profissão" e o campo dos "saberes e responsabilidades comuns ou confluentes a várias profissões" ${ }^{17}$. Esses conceitos possibilitam evidenciar os processos de cooperação e de mutação de cada profissão face às exigências do trabalho.

O trabalho em saúde é marcado fundamentalmente por algumas características: atende a necessidades complexas e variáveis; não pode ser totalmente padronizado, uma vez que envolve um encontro sempre singular entre sujeitos; os profissionais precisam de autonomia; é realizado por um grupo heterogêneo de trabalhadores; os médicos direcionam o processo assistencial; há dependência do ambiente sociopolítico; parte da força de trabalho é precarizada; e o cenário é de disputa entre atores com diversos interesses, o que demanda um processo de negociação permanente ${ }^{1,18}$. 
Para compreender o trabalho, a abordagem ergológica de Schwartz propõe o conceito de atividade, que é a maneira como as pessoas se engajam na gestão dos objetivos do trabalho, num lugar e tempo dados, servindo-se dos meios disponíveis ou inventando outros, para fazer frente às variabilidades e produzir sentido no trabalho. É um entrecruzamento de normas antecedentes e de tentativas de renormalização, na relação com o meio de vida, onde ocorre um debate permanente de valores que resultam em escolhas feitas pelos indivíduos e pelos grupos. As normas antecedentes são tudo que antecipa a atividade de trabalho que virá antes mesmo que a pessoa tenha começado a agir, tais como os protocolos, as normas e os saberes conceitualizados. As renormalizações são as múltiplas gestões de variabilidades, a transgressão de normas, assim como a construção de redes e da comunicação que toda situação de trabalho requer ${ }^{19-21}$.

Toda atividade de trabalho é sempre um dramático uso de si, no sentido de um drama, individual ou coletivo, que acontece quando eventos não esperados rompem com a sequência habitual e antecipável da vida, trazendo a necessidade de reagir, buscar alternativas e exigindo novas relações com o meio e entre as pessoas ${ }^{19}$. Nessa dialética de uso de si, o trabalhador faz uso de si mesmo em função do que os outros lhe demandam e do que ele próprio se demanda, e faz uso dos demais. Este jogo expressa o coletivo de trabalho.

"A atividade coletiva não pode ser calcada sobre a estruturação a priori de coletivos, mas evolui segundo as normas daqueles que trabalham juntos tentando construir no curso de sua experiência individual e coletiva de trabalho" 22 . Os coletivos são "entidades" variáveis no tempo e no espaço e se organizam para além dos organogramas, têm sua própria história. Nesse sentido constituem Entidades Coletivas Relativamente Pertinentes (ECRP), que estão presentes em toda organização. São entidades porque envolvem pessoas, mas as fronteiras do coletivo são invisíveis e variam conforme o conteúdo e o ritmo da atividade de trabalho; as pessoas podem pertencer a serviços diferentes e trabalhar juntas por compartilharem valores. São coletivas porque são vários trabalhadores buscando a eficácia e às vezes eficiência no seu trabalho. São pertinentes para compreender como o trabalho acontece. São relativas porque as fronteiras são variáveis, se formam a partir dos atos de trabalho, em função das pessoas, da necessidade de trabalharem juntas e da história das organizações ${ }^{2}$.

No contexto de complexidade da atenção primária de saúde, onde vários saberes e práticas são requeridos para enfrentar problemas nem sempre "tipicamente de saúde", as dramáticas se intensificam e torna-se um desafio agir com competência. Agir com competência implica em uma combinação dialética de diversos ingredientes integrando o saber agir (ter domínio das normas antecedentes), o querer agir (estar motivado ou aderir a um projeto coletivo) e o poder agir (capacidade de enfrentar os constrangimentos do meio $)^{23}$.

A interdisciplinaridade pode ser um caminho para integrar conhecimento e ação e qualificar o agir, na busca pela integralidade da atenção.

\section{Percurso metodológico}

A pesquisa ocorreu de abril a julho de 2005, em duas unidades de saúde de um município da Região Sul do Brasil. A população do estudo foi o conjunto dos alunos e supervisores locais que participaram de todo o curso, sendo 16 profissionais: entre os supervisores, 1 psicóloga, 1 médico, 2 enfermeiras e 1 farmacêutico; entre os residentes, 2 nutricionistas, 1 farmacêutica, 1 odontóloga, 4 médicos, 1 psicóloga e 2 enfermeiras. $\mathrm{O}$ contexto e os sujeitos da pesquisa foram escolhidos intencionalmente, sendo critérios de inclusão: profissionais de saúde integrantes de equipes multiprofissionais em saúde que atuavam no contexto do SUS, vivendo situações de trabalho que lhes demandavam prática interdisciplinar e com suporte teórico-prático permanente para o exercício desta prática, o que permitiria supor que estes estariam mais preparados para trilhar o caminho da interdisciplinaridade. Trata-se de um estudo qualitativo fundamentado no referencial teórico do processo de trabalho em saúde $\mathrm{e}^{1,2,24,25}$, da interdisciplinaridade $\mathrm{e}^{10,26-30}$ e da ergologia ${ }^{19-21,31}$.

Os dados foram obtidos através de entrevistas semiestruturadas, observação participante e grupo focal. A observação participante plena ${ }^{32}$ constituiu-se em um suporte para a definição do desenho da pesquisa, para a coleta e para a análise dos dados, devido ao fato da pesquisadora ter atuado como supervisora e professora dos residentes durante dois anos do curso. Ciente do risco epistemológico, alguns cuidados foram tomados: reconhecer rigorosamente os dados obtidos através dos instrumentos formais; usar a triangulação na coleta e na análise dos dados, o que permitiu olhar o fenômeno através de dados obtidos em diversas fontes e também, na análise de cada categoria, confrontar as informações; afastamento da pesquisadora do campo de pes- 
quisa no período da análise dos dados. $\mathrm{O}$ afastamento se deu durante seis meses para estudos no Departamento de Ergologia da Universidade AixMarseille I para aprofundamento do diálogo acadêmico nesta abordagem.

Os dados obtidos com as entrevistas e a observação foram analisados e organizados em précategorias, e levados para debate em dois grupos focais. As entrevistas foram codificadas com número e letra inicial da categoria profissional do entrevistado ou S de supervisor e o conteúdo do grupo focal identificado por GF.

A análise qualitativa seguiu os três passos (integrados) sugeridos por Demo ${ }^{33}$ : contextualização sócio-histórica, análise formal, e interpretação. O projeto de pesquisa foi aprovado no Comitê de Ética da Universidade Federal de Santa Catarina.

\section{Resultados e discussão}

A vivência da interdisciplinaridade foi expressa pelos sujeitos da pesquisa através de exemplos das atividades cotidianas de trabalho, bem como pelo relato das facilidades e dificuldades para a sua efetivação.

Duas grandes categorias surgiram nessa construção: "interdisciplinaridade - processo complexo e ação concreta" e "elementos facilitadores e dificultadores da interdisciplinaridade".

\section{Interdisciplinaridade - Processo Complexo e Ação Concreta}

A interdisciplinaridade se apresentou como um processo complexo em função da multiplicidade de recursos necessários para a sua efetivação. Recursos estes entendidos como tudo aquilo que precisa ser mobilizado para que o empreendimento interdisciplinar se efetive, incluindo, entre outros, saberes das mais diversas origens, ambiente favorável, projeto compartilhado e atitude dos sujeitos ${ }^{26-30}$.

O processo interdisciplinar apareceu como resultado de um processo de amadurecimento no trabalho em equipe e que necessita de um espaço institucional que possibilite a construção de novas normas e formas de realização do trabalho, a exemplo das interconsultas, que na experiência analisada constituiu-se em espaços de clínica em equipe.

Interdisciplinaridade não é só encaminhar, é um trabalho conjunto que vai desde o início até o final. No inicio o grupo tinha um pouco essa visão, mas com o tempo foi amadurecendo [...], é um trabalho conjunto, mesmo que não estejam os dois profissionais presentes numa consulta, mas que estejam integrados na resolução do problema. E acho que isso foi sendo construído, porque veio a história das interconsultas, como instrumento oficial da interdisciplinaridade [...] (8E).

A interdisciplinaridade, segundo os sujeitos, além de ser um processo de construção difícil e contraditório, às vezes parece ser um paradoxo, ela existe e não existe ao mesmo tempo, porque é difícil visualizá-la na vivência do dia a dia.

Acho que houve alguns momentos. O grupo amadureceu muito ao longo desses dois anos. [...] cada pessoa pode se abrir, mais umas com as outras, expor mais o que cada uma faz, cada área faz. [...] Antes [...] a gente conversava, mostrava o caso, alguém dava sugestões, mas a pessoa continuava a trabalhar sozinha e não tinha um acompanhamento. [Foi possível] trabalhar multiprofissional, mas não a interdisciplinaridade, que eu acho muito difícil (16P).

Havia uma tentativa de padronização das condutas dos profissionais, no sentido do trabalho integrado, mas fatores como o direcionamento médico no cuidado em saúde provocavam tensões e exigiam permanente negociação.

A gente percebia que havia diálogo, mas quando se voltava, por exemplo, com o usuário e com a família as atitudes continuavam as mesmas. A discussão, ela não tinha provocado realmente uma mudança [...] a última palavra era sempre a do médico. [...]. Eu acho isso uma questão muito complicada porque daí tem essa cara de trabalho interdisciplinar [...] (11S).

Saupe et al. ${ }^{34}$ também encontraram que a prática interdisciplinar é dinâmica e processual e que não é vivida da mesma maneira pelos profissionais. Segundo esses autores, "nem todos os momentos vividos numa Unidade de Saúde são interdisciplinares, não se é interdisciplinar o tempo todo e não se é interdisciplinar sempre, com todos os membros da equipe" ${ }^{34}$.

A complexidade dos problemas e da atenção à saúde foi reconhecida pelos sujeitos da pesquisa como mobilizador para o pensar e o agir interdisciplinar.

A complexidade dos problemas da população contribuiu para a interdisciplinaridade, para a percepção de que uma [profissão] não dá conta sozinha de um problema (1D).

Para alguns profissionais de saúde, a interdisciplinaridade era considerada meio de resolução de muitos problemas e, além disso, que as discussões em equipe multiprofissional já eram a inter- 
disciplinaridade acontecendo e o suficiente para tal. No entanto, na reflexão coletiva ocorrida no grupo focal sobressaiu a conclusão de que a interdisciplinaridade manifesta-se na realização da atividade, como ação concreta produtora de saberes e práticas, integrando conhecimento e ação.

A discussão tem que se transformar em ação. $O$ que [...] às vezes não acontece. Às vezes, a gente discute, discute, mas [...] a ação permanece a mesma. Eé justamente na ação que a gente vê a transformação daquela conduta. É onde tu vês que aquilo foi apropriado, fez sentido e houve modificação. Eu, às vezes, vejo que a gente discute, mas não muda o jeito de fazer (GF).

A interdisciplinaridade é prescrita na política de saúde e assumida pelos profissionais, mas existem lacunas entre o prescrito e o realizado. $\mathrm{Na}$ realização da atividade de trabalho, no sentido de Schwartz ${ }^{19}$ e Schwartz e Durrive ${ }^{20}$, os trabalhadores vivenciam uma dramática, fazendo escolhas que orientam a tomada de decisões. $\mathrm{Na}$ gestão dos elementos envolvidos no trabalho, a cada momento, os profissionais tomam decisões que nem sempre correspondem ao prescrito.

Os profissionais manifestaram que a interdisciplinaridade pode ser percebida como ação concreta ao produzir mudanças no processo de trabalho. Ao mesmo tempo, consideraram que se efetivou na realização conjunta do diagnóstico de saúde, no levantamento de problemas e no planejamento das ações. No mesmo sentido, a literatura também registra que a interdisciplinaridade "se constrói em cima de uma realidade muito concreta, ou seja, no âmbito das práticas, dos cotidianos, das demandas e necessidades" ${ }^{34}$.

As falas dos profissionais sobre a vivência da interdisciplinaridade sinalizaram um descompasso entre conhecimento e ação, ou seja, sugeriram a existência de consenso no plano dos valores e das normas antecipadoras do trabalho, mas no momento de agir existe a dificuldade de efetivar a cooperação e o trabalho integrado.

\section{Elementos Facilitadores e Dificultadores da Interdisciplinaridade}

Os resultados desta pesquisa mostraram que as facilidades e as dificuldades se entrecruzam e se transformam rearticulando e reconfigurando, permanentemente, as ações e os saberes envolvidos na sua execução, bem como redimensionam escolhas em uma relação dialética entre o contexto político institucional e a história de vida dos profissionais.

\section{O novo modelo ESF}

complexifica o trabalho

$\mathrm{O}$ atual contexto político institucional brasileiro de tentativas de mudança no modelo de atenção, materializado na prescrição da Estratégia de Saúde da Família, tem como ingredientes a complexidade dos problemas a serem enfrentados e as histórias dos indivíduos e dos coletivos. As tarefas exigidas para a configuração de um novo modelo multiprofissional e interdisciplinar fazem com que se ampliem interfaces a serem geridas pelos trabalhadores que compõem as equipes.

Por exemplo, [...] quantas vezes a gente não tem que falar sobre nutrição com o paciente, quantas vezes a gente não tem que orientar o paciente [...] porque ele está pedindo a aposentadoria, ou está pedindo seguro saúde, qualquer coisa. Eu sempre tento levar em consideração [...] todas estas disciplinas que permeiam a abordagem do paciente. Se eu estou explicando ao paciente [como usar um medicamento], ele começa me falar que - $A h$, [...] eu estou me incomodando em casa com o meu filho, eu não vou dizer para ele assim - está tudo bem, mas este medicamento tem que tomar as oito $e$ as oito. Se ele está falando aquilo, eu estou entendendo que ele tem algum outro problema que não é sobre o medicamento, [...] quer que eu o ajude, [...] tem que parar de falar sobre o medicamento e ouvir o que ele está me trazendo daquela queixa dele, ver como eu posso resolver o problema para ele $[. .$.$] (5S).$

Percebe-se que o enfrentamento do modelo biomédico intensifica o trabalho e exige a gestão de situações de trabalho que extrapolam o que teoricamente seria da competência do trabalhador, o que implica na ampliação dos saberes e das práticas de cada núcleo profissional. Colocase o desafio de articular a multiprofissionalidade, ou seja, a autonomia de cada profissão na relação com as demais, para realizar o cuidado em saúde, na busca da eficácia e da eficiência ${ }^{14}$. Segundo Schwartz e Durrive "a eficácia se obtém graças a um trabalho de apropriação normativa e de incessantes renormalizações, que no processo, articulam e redefinem saberes e valores" ${ }^{31}$.

A complexidade da atenção à saúde exige, ainda, o engajamento do profissional, a capacidade de escuta, o compromisso ético e a visão integral do sujeito do cuidado. O trabalho aparece como articulado à vida, exigindo quebra de preconceitos, mudança de atitude, e às vezes se confunde entre relações profissionais e pessoais.

Ter trabalhado dessa forma com os vários profissionais foi um crescimento para mim, acho que muito mais para minha vida pessoal até. Poder 
enxergar outras profissões, conviver, eu tinha certo ranço em relação a algumas profissões, e daí você vai conviver com eles e você vê, não, há profissionais que são assim, não é a profissão, é a pessoa $[\ldots] "(12 \mathrm{~N})$.

Segundo os sujeitos da pesquisa, o proposto na ESF é difícil de ser seguido, porque os serviços de saúde e os profissionais não estão preparados para lidar com a complexidade dos problemas de saúde, principalmente em populações com carências de todas as ordens.

A situação lá de saúde era muito dramática, o serviço pouco envolvido, poucos funcionários, eu me sentia perdido [...], porque os problemas erame continuam grandes, a fragilidade da situação de vida das pessoas lá é tão dramática que quando a residência chegou, eu disse - puxa vida dez profissionais chegando, a gente vai conseguir realmente avançar muito e na verdade, eu fui percebendo no decorrer do tempo de que isso não seria uma coisa tão rápida, por vários motivos:as visões de cada um, eram profissionais recém saídos dos seus cursos; a fragilidade dos nossos vínculos como supervisores locais e também pelo fato de não termos tido espaços para elaborar melhor a nossa forma de trabalho. Isto tudo foi uma construção [que] consumiu grande parte do nosso tempo e, talvez para uma próxima [...] a gente consiga avançar. Então, eu acho que eu tenho que reduzir o meu nível de ansiedade, mas ao mesmo tempo, a gente não pode permitir que esta ansiedade diminua demais, por que os problemas das pessoas e, às vezes, a não resolução destes problemas pode resultar em prejuízo muito grande pra vida das pessoas [...] (4S).

$\mathrm{Na}$ ESF os profissionais devem atuar sobre os determinantes do processo saúde doença, rompendo com o modelo focado na atenção à demanda espontânea e à doença ${ }^{14}$, o que provoca um exercício permanente de reflexão sobre os próprios atos e no que eles irão resultar.

O trabalho requer um triplo engajamento: com o mundo, com os outros e consigo mesmo. A exigência de eficácia coloca o trabalhador num permanente debate de normas e valores ${ }^{31}$. Um cenário como este é composto por elementos de sofrimento, frustrações, ansiedades e dificuldades de agir nas situações de trabalho. Os sujeitos se angustiavam diante das poucas possibilidades de intervir no processo saúde-doença para além do aspecto biológico, porque, segundo eles, resolver a doença tem resultado visível imediato, mas mexer no social é demorado.

\section{Transitar entre o multi e o inter não é simples}

Os profissionais de maneira geral pareciam confusos, sem saber como se mover entre os limites imprecisos do campo e do núcleo de competências e de responsabilidades pelo cuidado em saúde, o que poderia estar relacionado ao fato de terem pouco tempo de formação e de experiência profissional.

[...] às vezes, ficava meio vago o que se queria da interdisciplinaridade. Por que de um lado tu querias a interdisciplinaridade, mas, do outro tu precisavas que as profissões se fortalecessem, tivessem a competência específica. Parece que eram coisas antagônicas, ou tu fazias um trabalho interdisciplinar ou tu eras bom na tua profissão de origem (14M).

[...] Essa dificuldade de trocar experiências com as outras áreas faz parte do próprio processo da construção do trabalho interdisciplinar. [...] como é um processo que se constrói no cotidiano, ele se constrói com a história das pessoas que estão lá (GF).

A observação participante permitiu visualizar que toda a equipe planejava e executava ações em conjunto quando estas eram voltadas para a coletividade. No entanto, na Unidade de Saúde, trabalhavam em geral isoladamente, cada um cuidando daquele "pedaço do ser humano", típico do modelo biomédico. No decorrer do curso, essa situação timidamente foi se modificando, com a instituição da Interconsulta como espaço de clínica em equipe, e dos Momentos de Integração (MI) criados para impulsionar a elaboração de planos terapêuticos em equipe e a intervenção conjunta. Observou-se que no trabalho ocorreram mutações no núcleo de competências as quais foram articulando, rearticulando e redefinindo, de alguma maneira, lugares e autonomias, conformando o coletivo de trabalho.

A interdisciplinaridade, segundo os sujeitos da pesquisa, acontecia nos momentos de planejamento, nos atendimentos conjuntos e quando trocavam saberes para os atendimentos profissionais específicos. Caracterizava-se pelo estabelecimento de um plano terapêutico comum, pela atitude em trocar saberes, pela liberdade de "invadir" o atendimento do outro e pela liberdade, também, do usuário participar das decisões sobre o seu processo terapêutico.

Constituíam-se Entidades Coletivas Relativamente Pertinentes (ECRP) ${ }^{22}$ expressando as microrrecomposições dos coletivos de trabalho em torno da equipe e dos usuários, na busca da eficácia. Eram situações de trabalho em movimento, nas quais a equipe ou os profissionais desen- 
volviam ações ou atividades de atenção à saúde, de caráter individual ou coletivo, ora fragmentadas, ora integradas, precedidas de um planejamento coletivo ou não.

A atitude dos sujeitos de comprometimento com o cuidado das pessoas, mesmo diante de adversidades, apareceu como um potencializador do trabalho da equipe. A atitude implica não se deixar limitar pelas antecipações, se autorizar a recriar normas em nome daqueles que são sujeitos do cuidado e a interpretar e questionar as normas que são impostas.

A situação de trabalho é o lugar, segundo Schwartz ${ }^{19}$ e Schwartz e Durrive ${ }^{20}$, de uma dramática subjetiva onde são negociadas em circunstâncias pessoais, históricas, sempre particulares, as modalidades dos compromissos entre normas hetero e autodeterminadas, entre uso de si pelos outros e uso de si por si.

\section{Dificuldades de compartilhar saberes}

Segundo os entrevistados, alguns fatores contribuíram como limitadores para que os profissionais compartilhassem seus saberes no trabalho em equipe, tais como a fragilidade do núcleo de competência profissional, a não valorização do seu próprio trabalho, dificuldades pessoais, timidez, imaturidade, medo de errar, disputas de poder, desconhecimento de como trabalhar de forma interdisciplinar, e limitações da formação na graduação. A questão do poder médico estava sempre presente, bem como a dificuldade das demais profissões de saúde de lidar com essa problemática.

E aí eu fico pensando, até que ponto eu não fiquei nesse papel de passivo, de ser convidado para discutir um processo terapêutico. Será que também eu não tinha um pouco de medo, já que eu não tinha muitos conhecimentos a respeito da terapia $[. .].(13 \mathrm{~F})$.

[...] dificuldade de entender os papeis, a disputa de poder, a dificuldade de reconhecer a importância do saber do outro, porque o médico éo Deus, então há uma hierarquia. A enfermeira abaixo do médico, a nutricionista só fala de comida, o psicólogo é pra conversar (1D).

A medicina é o grande vilão da história, mas as ciências humanas também têm dificuldades de inserir o biológico nas suas discussões, têm os seus tabus. [...]. Todo objeto para mim é complexo quando tu trabalhas com a realidade. Então, exige as várias abordagens (GF).

Para os profissionais, o que influenciava predominantemente o processo de tomada de decisão na equipe eram as características pessoais dos indivíduos e as relações que se estabeleciam entre eles.

Acho que atrapalha bastante a falta de iniciativa de algumas pessoas, até minha. Alguns mais autoritários outros mais sentimentalistas, como eu. As pessoas se respeitavam, a gente procurava conversar, esclarecer as coisas, ser o mais sincero possível. Às vezes, era difícil, [...] (9E).

Se fala muito da formação acadêmica. Eu vou falar da formação pessoal dos sujeitos. Que tem a ver com o modelo de sociedade, com a cultura, a lógica que tu és educada. Se tu és educado a ser uma pessoa competitiva, que não sabe trabalhar em equipe, é muito difícil você se tornar um adulto e aprender a trabalhar dessa forma. Tu vais apanhar [...]. Ou, tu vais buscar equipes que trabathem dessa forma, cada um faz seu trabalho isolado. Então, as pessoas buscam trabalhos por afinidades pessoais também (GF).

Toda situação de trabalho supõe, no uso dramático de si, experiências, "arbitragens, ponderações, critérios, portanto engajamento" ${ }^{35}$, mais ou menos conscientes, construídos ao longo de um processo de renormalizações que se transformam em patrimônio não só para o trabalho, mas para a vida dos sujeitos. Segundo Schwartz, nosso "corpo-si", durante a vida, é colocado à prova, se historiciza através dos entrecruzamentos de normas e valores e cada renormalização é um momento de escolha, de ressingularização de nós mesmos e que possibilita o enfrentamento do meio hostil ${ }^{36}$. Isso significa que os profissionais têm potencialidades e podem desenvolver a capacidade de agir diferente.

\section{O contexto político-institucional influenciando a interdisciplinaridade}

O contexto político-institucional e a estrutura do sistema de saúde, incluindo a organização, a gestão dos serviços de saúde e a cultura institucional, também influenciaram a interdisciplinaridade. $\mathrm{O}$ contexto inclui ainda os elementos organizativos e estruturais do curso de residência.

Foi unânime entre os profissionais que as práticas de atenção à saúde nas Unidades Básicas não correspondem ao que é preconizado pelo Ministério da Saúde, ou seja, para eles, havia um modelo teórico de como trabalhar, em aprendizagem no curso de Residência, que não se coadunava com o trabalho cotidiano dos serviços.

O modelo novo quem vai fazer é a gente. Eu não fui formado para ir trabalhar num lugar que está esperando um profissional novo. [...], eles não estão esperando alguém que vá fazer acolhimento, que vá fazer planejamento [...]. Eles estão esperan- 
do o médico que vai chegar lá e atender a demanda (14M).

O serviço não tem clareza de que é possível fazer um trabalho mais multiprofissional e interdisciplinar, as discussões dentro da instituição sobre trabalho inter são muito incipientes (4S).

[...] Uma equipe do PSF trabalhando como é previsto eu não conhecia. A gente estudava [...], mas na prática não era o que se apresentava e nós como residentes não conseguíamos implementar isso $(3 \mathrm{M})$.

Um modelo é uma prescrição generalizante, descontextualizada, que, ao ser aplicado a uma realidade concreta, se efetiva de acordo com as singularidades locais. Todo lugar de trabalho tem suas próprias normas antecedentes que orientam as escolhas dos indivíduos e coletivos, e parte delas é criada a partir da atividade de trabalho e não está escrita em nenhum lugar ${ }^{31}$. Além disso, as antecipações do trabalho não são suficientes para a eficácia face à complexidade do fazer, sendo assim as normas são renormalizadas permanentemente e ao mesmo tempo pode haver vazios de normas que poderiam tornar o trabalho mais resolutivo. O profissional recente na equipe vai precisar de um tempo para se apropriar do que está implícito nas situações de trabalho e para ampliar a sua capacidade de agir diante dos constrangimentos do meio.

Como eu falei, tem profissionais e profissionais. Agora, a gente está com CTD [contrato por tempo determinado], de seis em seis meses, como é que você vai fazer um trabalho interdisciplinar? A gente ainda tem um desfalque da equipe. Só temos uma equipe PSF. [As outras] equipes são contratadas. Mas de seis em seis meses muda tudo, auxiliar, enfermeiro, médico (7S).

Mas pensando nos funcionários, o que a gente aprende é o quanto uma gestão de um município influencia o fazer saúde. Se os funcionários estão mal-humorados, se existe muito afastamento por doença, então eu acho que tudo isso é reflexo da gestão. Não percebi outra contribuição do serviço que não fosse isso, mostrar a quase crueldade da realidade do trabalho em saúde desses profissionais (13F).

Refletir sobre as possibilidades de construção de um trabalho interdisciplinar é complexo e deve-se considerar uma variedade de elementos influenciando nesse processo. Um contexto como o da pesquisa vai exigir mais do coletivo e pode dificultar a cristalização de experiências, processos esses nem sempre visíveis, difíceis de avaliar, mas que muitas vezes aparecem como sendo resistências dos trabalhadores às mudanças. Espa- ço e tempo compartilhado são importantes para que as pessoas se conheçam, troquem e construam vínculos entre si. A construção do coletivo depende de haver um mínimo de estabilidade e de certa permanência no emprego e na organização, porque a confiança e a cooperação se constroem com o tempo pelo conhecimento da forma de trabalhar.

Observou-se que os residentes contavam com espaço e tempo propícios ao trabalho interdisciplinar. Eram seis categorias profissionais com seus respectivos supervisores buscando uma atuação conjunta e contribuindo para a vivência da interdisciplinaridade. Atividades estruturadas dentro e fora da unidade de saúde eram orientadas pelos princípios da interdisciplinaridade, integralidade e intersetorialidade.

Entretanto, muitos supervisores não eram preparados para lidar com uma complexidade tão grande e não tinham conteúdo suficiente de saúde pública. Cada um orientava no seu núcleo de saber, isso confundia o residente (11S).

$\mathrm{O}$ agir humano só pode ser compreendido na sua relação com o meio, relação esta sempre permeada por certa tensão diante das adversidades. Como relatado na literatura, o contexto de instabilidade trabalhista, a inadequação da formação, o foco na atenção à demanda e o predomínio do modelo médico centrado persistem como desafios para efetivar a $\mathrm{ESF}^{37}$.

\section{Conclusões}

Este estudo revelou que a interdisciplinaridade requer uso integrado de conhecimentos na prática multiprofissional, invasão das fronteiras disciplinares, desenvolvimento de competências para lidar com os desafios do meio e atitude individual como componente fundamental para o agir profissional.

O trabalho multiprofissional na perspectiva interdisciplinar apareceu como possibilidade concreta no plano intelectual, mas na prática era orientado predominantemente pelo modelo biomédico hegemônico. Além de se mostrar dependendo da consciência e do compromisso dos profissionais, de conhecimentos e competências, envolvendo a subjetividade e a intersubjetividade dos atores, o trabalho é condicionado pelo modelo de gestão e pelas condições materiais e organizacionais nas quais se desenvolvem as atividades de trabalho.

O modelo Saúde da Família complexifica o trabalho. Atuar segundo o princípio da integra- 
lidade na atenção primária amplia as interfaces a gerir e coloca novas dificuldades e desafios no plano das competências, questões que devem ser consideradas ao se pensar sobre o potencial de cada profissional e as possibilidades dos coletivos trabalharem interdisciplinarmente.

A pesquisa evidenciou a dimensão de uso de si presente na relação com os usuários ao produzir "desvios" no que havia sido planejado pelo profissional. A busca de eficácia provoca o debate de normas e valores e a renormalização das normas antecedentes, e também leva o trabalhador a reinventar seu modo de trabalhar.

Conclui-se que a interdisciplinaridade não tem um fim em si mesmo, não está presente em todos os momentos e se constrói a partir de necessidades e capacidades determinadas pelo meio e pelos sujeitos que produzem o cuidado em saúde.

\section{Colaboradores}

MDA Scherer, R Jean e D Pires participaram igualmente de todas as etapas de elaboração do artigo

\section{Referências}

1. Pires D. Reestruturação produtiva e trabalho em saúde. 2a Edição. São Paulo: Annablume; 2008.

2. Scherer MDA, Pires D, Schwartz Y. Trabalho coletivo: um desafio para a gestão em saúde. Rev Saude Publica 2009; 43(4):721-725.

3. Nunes ED. A questão da interdisciplinaridade no estudo da saúde coletiva e o papel das ciências sociais. In: Canesqui AM, organizadora. Dilemas e desafios das ciências sociais na saúde coletiva. São Paulo, Rio de Janeiro: Hucitec, Abrasco; 1995. p. 95-113.

4. Paim JS. Saúde da Família: espaço de reflexão e de contra-hegemonia. Interface (Botucatu) 2001; 5(9): 143-146.

5. Minayo MCS. Estrutura e sujeito, determinismo e protagonismo histórico: uma reflexão sobre a práxis da saúde coletiva. Cien Saude Colet 2001; 6(1):7-19.

6. Almeida MCP, Mishima SM. O desafio do trabalho em equipe na atenção à saúde da família: construindo "novas autonomias" no trabalho. Interface (Botucatu) 2001; 5(9):150-153.

7. Meirelles BHS, Erdman AL. A interdisciplinaridade como construção do conhecimento em saúde e enfermagem. Texto Contexto Enferm 2005; 14(3):411418. 
8. Minayo MCS. O desafio do conhecimento: pesquisa qualitativa em saúde. 10a Edição. São Paulo: Hucitec; 2007.

9. Saintrain MVL, Vieira LJES. Saúde bucal do idoso: abordagem interdisciplinar. Cien Saude Colet 2008; 13(4):1127-1132.

10. Luz M. Complexidade do Campo da Saúde Coletiva: multidisciplinaridade, interdisciplinaridade, e transdisciplinaridade de saberes e práticas - análise sócio-histórica de uma trajetória paradigmática. Saúde Soc 2009; 18(2):304-311.

11. Guedes LM, Ferreira Junior M. Relações Disciplinares em um Centro de Ensino e Pesquisa em Práticas de Promoção da Saúde e Prevenção de Doenças. Saúde Soc 2010; 19(2):260-272.

12. Borges MJL, Gurgel IGD, Sampaio AS. Trabalho em equipe e interdisciplinaridade: desafios para a efetivação da integralidade na assistência ambulatorial às pessoas vivendo com HIV/Aids em Pernambuco. Cien Saude Colet 2010; 17(1):147-156.

13. Minayo-Gomes C, Thedim-Costa SMF. A construção do campo da saúde do trabalhador: percursos e dilemas. Cad Saude Publica 1997; 13(Supl.2):21-32.

14. Brasil. Portaria MS/GM no 2.488, de 21 de outubro de 2011. Aprova a Política Nacional de Atenção Básica, estabelecendo a revisão de diretrizes e normas para a organização da Atenção Básica, para a Estratégia Saúde da Família (ESF) e o Programa de Agentes Comunitários de Saúde (PACS). Diário Oficial da União 2011; 24 out.

15. Mendes EV. Uma agenda para a saúde. São Paulo: Hucitec; 1996.

16. Scherer MDA, Pires D. Interdisciplinaridade: processo complexo de conhecimento e ação. Revista Tempus Actas de Saúde Coletiva 2011; 5(1):69-84.

17. Campos GW. Saúde pública e saúde coletiva: campo e núcleo de saberes e práticas. Cien Saude Colet 2000; 5(2):219-230.

18. Dussault G. A Gestão dos serviços públicos de saúde: características e exigências. Rev Adm Publica 1992; 26(2):8-19.

19. Schwartz Y. Reconnaissances du travail: pour une approche ergologique. 2a Edição. Paris: PUF; 1998.

20. Schwartz Y, Durrive L. Travail \& Ergologie: entretiens sur l'activité humaine. Toulose: Octarés; 2003.

21. Rosa MI. Usos de si e densificação do trabalho. In: Dieese, CESIT, organizadores. Trabalho e abordagem pluridisciplinar: estudos Brasil, França e Argentina. São Paulo, Campinas: Dieese, CESIT; 2005. p. 17-33.

22. Efros D, Duc M, Faita D. Travailler ensemble? In: Schwartz Y. Reconnaissances du travail: pour une approche ergologique. 2a Edição. Paris: PUF; 1998. p. 57-58.

23. Schwartz Y. Os ingredientes da competência: um exercício necessário para uma questão insolúvel. Educ. Soc 1998; 19(65):101-139.

24. Peduzzi M. Equipe multiprofissional de saúde: conceito e tipologia. Rev Saude Publica 2001; 35(1):103109.
25. Ribeiro EM, Pires D, Blank VLG. A teorização sobre processo de trabalho em saúde como instrumental para análise do trabalho no Programa Saúde da Família. Cad Saude Publica 2004; 20(2):438446.

26. Japiassu H. Interdisciplinaridade e patologia do saber. Rio de Janeiro: Imago; 1976.

27. Fazenda ICA. Interdisciplinaridade: um projeto em parceria. São Paulo: Edições Loyola; 1991.

28. Frigotto G. A interdisciplinaridade como necessidade e como problema nas ciências sociais. In: Jantsch AP, Bianchetti L, organizadores. Interdisciplinaridade: para além da filosofia do sujeito. Petrópolis: Vozes; 1995.

29. Morin E. Por uma reforma do pensamento. In: Pena-Vega A, Nascimento EP, organizadores. O pensar complexo: Edgar Morin e a crise da modernidade. 3a Edição. Rio de Janeiro: Garamond; 1999. p. 21-46.

30. Di Ruzza R. L’Aventure ergologique. In: Di Ruzza R, Halevi J, organizadores. De l'economie politique à l'ergologie - lettre aux amis. Paris: Éditions L'Harmattan; 2003. p.51-85.

31. Schwartz Y, Durrive L. Travail \& Ergologie: entretiens sur l'activité humaine II. Toulose: Octarés; 2009.

32. Cruz Neto O. O trabalho de campo como descoberta e criação. In: Minayo MCS, organizador. Pesquisa social: teoria, método e criatividade. Petrópolis, RJ: Vozes; 1994. p. 51-66.

33. Demo P. Pesquisa e informação qualitativa. 2a Edição. São Paulo: Papirus; 2004.

34. Saupe R, Cutolo RLA, Wendhausen ALP, Benito GAV. Competência dos profissionais de saúde para o trabalho interdisciplinar. Interface (Botucatu) 2005; 9(18):521-536.

35. Schwartz Y. Trabalho e valor. Tempo soc 1996; 8(2):147-158.

36. Schwartz Y. Qual sujeito para qual experiência? $R$ Tempus Actas Saúde Col 2011; 5(1):55-67.

37. Costa GD, Cotta RMM, Ferreira MLSM, Reis JR, Franceschini SCC. Saúde da Família: desafios no processo de reorientação do modelo assistencial. Rev Bras enferm 2009; 62(1):113-118.

Artigo apresentado em 15/06/2012

Aprovado em 28/08/2012

Versão final apresentada em 17/09/2012 